\title{
Mitigating The Burden Of Diabetes In Sub-Saharan Africa Through An Integrated Diagonal Health Systems Approach
}

This article was published in the following Dove Press journal: Diabetes, Metabolic Syndrome and Obesity: Targets and Therapy

\author{
Tim Mercer (1D \\ Alice C Chang $\mathbb{D}^{2}$ \\ Lydia Fischer ${ }^{3}$ \\ Adrian Gardner (iD) ${ }^{4-6}$ \\ Immaculate Kerubo (D) $^{7,8}$ \\ Dan N Tran (iD) \\ Jeremiah Laktabai $\mathbb{D}^{10}$ \\ Sonak Pastakia $\mathbb{D}^{7,9}$ \\ 'Department of Population Health, The \\ University of Texas at Austin Dell Medical \\ School, Austin, TX 787I2, USA; \\ ${ }^{2}$ Genentech Inc., San Francisco, CA, USA; \\ ${ }^{3}$ Department of Child Psychiatry, Indiana \\ University School of Medicine, \\ Indianapolis, IN 46202, USA; \\ ${ }^{4}$ Department of Medicine, Indiana \\ University School of Medicine, \\ Indianapolis, IN 46202, USA; \\ ${ }^{5}$ Department of Medicine, Moi University \\ School of Medicine, Eldoret, Kenya; \\ ${ }^{6}$ Indiana Institute for Global Health, \\ Indianapolis, IN 46202, USA; \\ ${ }^{7}$ Department of Pharmacology and \\ Toxicology, Moi University School of \\ Medicine, Eldoret, Kenya; ${ }^{8}$ National \\ Spinal Injury Referral Hospital, Nairobi, \\ Kenya; 'Department of Pharmacy \\ Practice, Purdue University College of \\ Pharmacy, Purdue Kenya Partnership P.O. \\ Box 5760, Eldoret 30100, Kenya; \\ ${ }^{10}$ Department of Family Medicine, Moi \\ University School of Medicine, Eldoret, \\ Kenya
}

Correspondence: Sonak Pastakia Department of Pharmacy Practice, Purdue Kenya Partnership, Purdue University College of Pharmacy, P.O. Box 5760, Eldoret 30100, Kenya

Email spastaki@gmail.com

\begin{abstract}
Diabetes is a chronic non-communicable disease (NCD) presenting growing health and economic burdens in sub-Saharan Africa (SSA). Diabetes is unique due to its cross-cutting nature, impacting multiple organ systems and increasing the risk for other communicable and non-communicable diseases. Unfortunately, the quality of care for diabetes in SSA is poor, largely due to a weak disease management framework and fragmented health systems in most sub-Saharan African countries. We argue that by synergizing diseasespecific vertical programs with system-specific horizontal programs through an integrated disease-system diagonal approach, we can improve access, quality, and safety of diabetes care programs while also supporting other chronic diseases. We recommend utilizing the six World Health Organization (WHO) health system building blocks - 1) leadership and governance, 2) financing, 3) health workforce, 4) health information systems, 5) supply chains, and 6) service delivery - as a framework to design a diagonal approach with a focus on health system strengthening and integration to implement and scale quality diabetes care. We discuss the successes and challenges of this approach, outline opportunities for future care programming and research, and highlight how this approach can lead to the improvement in the quality of care for diabetes and other chronic diseases across SSA.
\end{abstract}

Keywords: diabetes, sub-Saharan African, integrated diagonal health systems approach, health system building blocks, health system strengthening, health system integration

\section{Introduction}

The global burden of non-communicable disease (NCDs) is staggering, with recent reports highlighting that NCDs are responsible for $73 \%$ of deaths globally, with more than $50 \%$ of these deaths caused by four risk factors: diabetes, hypertension, obesity, and smoking. ${ }^{1}$ In sub-Saharan Africa (SSA), diabetes mellitus is estimated to affect 40.7 million people by 2045 , up from 15.9 million people in $2017 .^{2}$ This burden is further exacerbated by estimates which show that more than two-thirds of individuals in SSA with diabetes are undiagnosed. ${ }^{3}$ Given the increasing demand and inadequate funding for diabetes care, the quality of care for diabetes in SSA is poor. ${ }^{4}$ Furthermore, diabetes carries a significant "double burden" of infectious and chronic diseases. ${ }^{5}$ It can increase the risk of other non-communicable conditions such as cardiovascular and renal disease, as well as communicable conditions such as pneumonia and tuberculosis. ${ }^{6}$ As a lifelong illness, diabetes is a multifaceted disease, affecting multiple organ systems and characterized by periods of acute exacerbations, requiring a comprehensive, cross-cutting, and often high-cost approache to successfully manage. ${ }^{7}$ To 
provide sustainable, comprehensive diabetes management, it is essential to integrate disease-specific care programs for diabetes into all other system-wide functions of the health system, such as leadership and governance, financing, health workforce, health information systems, supply chains, and service delivery. ${ }^{8}$

The growing demand for diabetes care, the enormous economic burden diabetes poses, and the cross-cutting nature of the disease and its ensuing complications all have major implications for how diabetes care is delivered in SSA. ${ }^{7,8}$ We argue that by synergizing disease-specific vertical programs with system-specific horizontal programs through an integrated disease-system diagonal approach, we can improve access, quality, and safety of diabetes care programs. In order to assess the merits of this approach for diabetes, we performed a thorough review of the peer-reviewed literature by querying Pubmed in addition to websites of reputable global organizations (i.e. World Bank, World Health Organization [WHO], International Diabetes Federation [IDF]) to identify evidence describing the relevance of using a diagonal approach for diabetes care in LMIC settings in SSA. We utilized the six WHO health system building blocks - 1) leadership and governance, 2) financing, 3) health workforce, 4) health information systems, 5) supply chains, and 6) service delivery - as a framework to design a diagonal approach with a focus on health system strengthening and integration to implement and scale quality diabetes care. ${ }^{9}$ We also discuss the successes and challenges of this approach, outline opportunities for future care programming and research, and highlight how this approach may lead to the improvement in the quality of care for diabetes and other chronic diseases across SSA.

\section{Defining The Diagonal Approach To Health System Strengthening And Integration}

It has been argued that health systems in low- and middleincome countries (LMICs), including countries within SSA, are often segmented and fragmented making it difficult for patients to navigate a divided care system. ${ }^{4,8,10}$ In the past, vertical and horizontal approaches to global health have both been used in health systems planning. ${ }^{11,12}$ The vertical approach refers to a health system that focuses on management of a single disease and builds infrastructure dedicated to managing that particular disease only. ${ }^{11}$ This approach is commonly used in LMIC settings with limited funding to provide immediate response and management to disease outbreaks due to the relative ease of setting up as compared to other schemes. Various highlights such as the drastic reduction in new HIV cases through HIV/AIDS control programs or success in polio eradication programs have led to its popularity. ${ }^{11}$ On the contrary, the horizontal approach promotes health services that strengthen infrastructure and functions of the entire health system. ${ }^{13}$ Health programs designed using this approach are common in developed countries and have been referred to as "more integrated, demand-driven, resource sharing health services."11,14

Vertical and horizontal approaches both have challenges and shortfalls. On one hand, vertical programs are often unsustainable in the absence of donor support and sometimes have detrimental effects on other aspects of the healthcare system as it draws resources from other aspects to unilaterally focus on one disease. ${ }^{10,11}$ On the other hand, horizontal programs and their impacts are often diluted by trying to address the myriad issues that health systems in LMICs face. ${ }^{15}$ As a result, a diagonal approach seeks to merge the strengths of the vertical and horizontal approaches while avoiding many of their disadvantages. ${ }^{16}$ It combines the immediate advantages of the vertical system as well as the long-standing benefits of the horizontal system. ${ }^{15,17}$ Through synergistic integration, disease-specific programs are incorporated in the many health system functions, leading to overall health system strengthening and integration. ${ }^{11,18,19}$

\section{A Proposed Diagonal Approach For Diabetes Care Implementation And Scale-Up}

Delivering diabetes care in a vertical, disease-specific programming and financing model is costly, inefficient, ineffective, and unsustainable over the long term. As a result, a diagonal approach is particularly appealing for diabetes because of the multiple organ systems it impacts and the complementarity of its management with the many other chronic diseases experienced by patients in SSA, as seen in Figure 1.

\section{Leadership/Governance}

Well-rounded leadership and governance are key to maintaining an effective and sustainable healthcare system. All individual patients, their families, and health workers can play leadership roles in health development. ${ }^{20}$ Yet, many 


\section{Functional Diabetes \\ Care System}

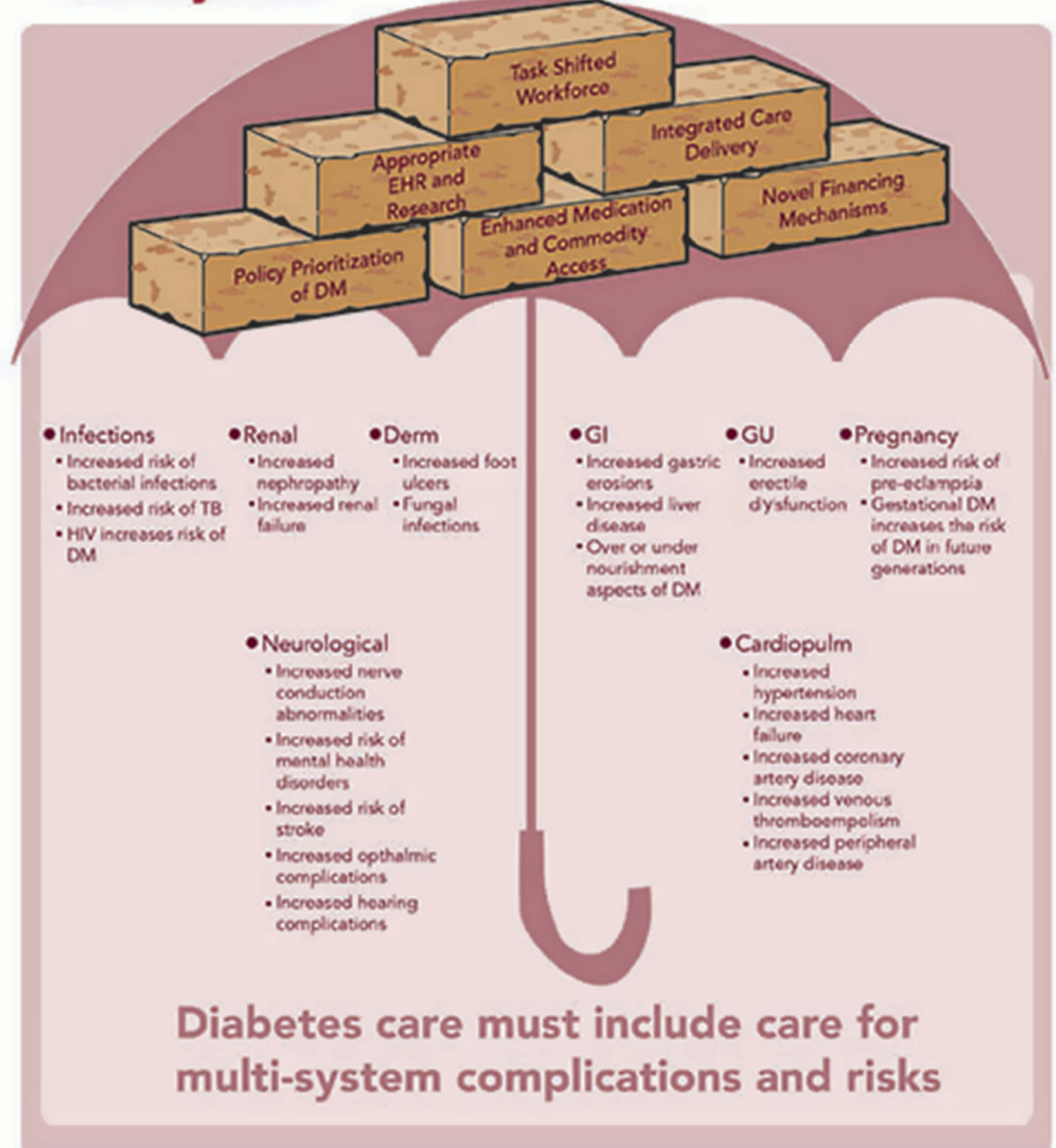

Figure I Functional diabetes care system as a framework for comprehensive population health.

countries in SSA lack a clear political leadership and advocacy framework for diabetes. ${ }^{21}$

To address inadequate support from governments, a modified framework on health development governance was suggested to be applied to the WHO African region. ${ }^{20}$ Strong public health leadership and management, effective internal and external partnership for health, efficiency in resource allocation and use, and community participation and responsiveness are critical strategies for strengthening the leadership and governance structures to improve diabetes care. ${ }^{20}$ The
Diabetes Action Now campaign initiated by the IDF and the WHO aimed to improve the effectiveness of surveillance, prevention, and control of type 2 diabetes, providing strategic policy direction and oversight at a multi-national level. ${ }^{21} \mathrm{In}$ Tanzania, the Ministry of Health (MOH) collaborated with the Tanzanian Diabetes Association to set up a network of diabetes clinics throughout the country. ${ }^{21}$ The significance of the MOH National Eye Care Plan was also recognized in Botswana, Ghana, Tanzania, and Zambia for prevention of diabetic retinopathy. ${ }^{22}$ Recognizing the heavy burden of 
diabetic retinopathy and visual impairment and blindness in patients in LMICs, the WHO also created a standardized tool for the assessment of diabetic retinopathy and diabetes management systems (TADDS). ${ }^{23}$ This tool is to assist countries with situation analysis, service provision capability, and identification of gaps to be addressed to ensure access to diabetes care and prevention and treatment of diabetic retinopathy. In addition to the aforementioned strategies directly addressing health outcomes, policies tackling food availability, cash crops, and urbanization are equally essential in combating

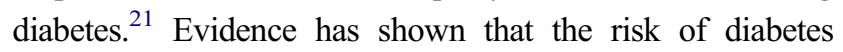
increases with concomitant micronutrient deficiencies and the rising issues of malnutrition and unhealthy lifestyle practices. $^{24}$ The Integrated Nutrition Program was thus established in South Africa to reduce nutrition-related diseases of lifestyle such as type 2 diabetes. $^{25}$

The WHO also established the Global Action Plan for the Prevention and Control of NCDs to reduce death caused by cardiovascular diseases, chronic respiratory diseases, cancers, and diabetes by $25 \%$ by $2025 .^{26}$ The WHO utilizes national-level taxes and legislation, and leverages the experience of HIV/AIDS health programs to combat tobacco use, harmful use of alcohol, physical inactivity, and unhealthy diet. $^{26}$ Taking the socioeconomic determinants of diabetes into account can help resolve the fundamental causes of health disparities. Leveraging multinational entities such as the WHO and IDF can strengthen the leadership and governance structure for the advancement of the entire health system.

An integrated and comprehensive approach to diabetes management cannot overlook issues surrounding social determinants of health (SDH), a concept spearheaded by the WHO. SDH are the conditions in which "people are born, grow, work, live, and age, and the wider set of forces and systems shaping the conditions of daily life." 27 Time and time again, SDH such as low income, low educational attainment, employment insecurity, poor living conditions, inconsistent access to nutritious food, essential medications and supplies are demonstrated to play a key role in the development and progression of diabetes worldwide. ${ }^{28}$ Focusing on biological and behavioral factors alone, without addressing SDH and their impact on diabetes burden will not adequately address diabetes management, and will continue to present as a barrier to the improvement of diabetes. The WHO Commission on SDH (CSDH) has been fighting for equity and fair distribution of health care resources since 2005. However, patients living with diabetes and their family members must also demand and advocate with their providers, their communities, and their health authorities to provide the physical and mental health resources to enable them to better manage their care needs.

Diagonally incorporating diabetes care into the broader health system can promote leadership and governance to address the broad spectrum of diabetes as effective interventions for all of these diseases require comprehensive interventions which consider socioeconomic, nutritional, and environmental perspectives in SSA.

\section{Financing}

The financing of diabetes care has created a heavy burden on both the society and individual patients. Unlike HIV, $\mathrm{TB}$, and malaria which received more than $99 \%$ of the healthcare assistance from the US to LMICs in 2010, diabetes receive only limited outside assistance. ${ }^{29}$ While it is clear that diabetes care in SSA would greatly benefit from a coordinated response similar to what was seen with HIV through the President's Emergency Plan for AIDS Relief (PEPFAR), it is unlikely to happen and creative locally financed solutions must be sought.

The economic burden of diabetes includes direct costs due to healthcare and indirect costs due to workforce losses. ${ }^{30}$ The total economic loss in SSA was more than 11 billion dollars with $56.9 \%$ of it as direct costs and $43.1 \%$ as indirect costs. ${ }^{30}$ The high rate of indirect costs in SSA can be explained by the peak prevalence in the age groups of 20 to 44 and 45 to 64 years in SSA, affecting the most economically productive portion of the population. ${ }^{30}$ This double burden of diseases on people of working ages aggravates the economic impact of diabetes similar to HIV during the height of epidemic in SSA.

The costs of treatment for diabetes and its complications are significant as well. To treat diabetes itself, the cost of a $10 \mathrm{~mL} 100 \mathrm{IU} / \mathrm{mL}$ vial of insulin can range from $\$ 4.10$ to $\$ 8.40 .^{31}$ The monthly cost of routine diabetes care is US\$ 21.2 in Mali, accounting for almost $70 \%$ of the mean income. ${ }^{32}$ In Nigeria, the monthly direct cost of routine diabetes care for children and adolescents was around US $\$ 73$ with insulin making up $51.5 \%$ of it. ${ }^{33}$ Diabetes treatment costs can reach more than twice the non-food expenditure per month in the poorest quartile of the patient population in Nigeria. ${ }^{34}$ For oral hypoglycemic agents specifically, a monthly regimen of metformin would cost more than 3 days' worth of wages in Kenya and more than 6 days' worth of wages in Ghana. ${ }^{35}$ On top of the treatment costs for diabetes, the cost of care for its complications can also be overwhelming as diabetes uniquely affects multiple organ 
systems as seen in Figure 1. Some common complications and comorbidities include infectious diseases, neurological, cardiopulmonary, gastrointestinal, renal, genitourinary, dermatological, and pregnancy conditions. ${ }^{7}$ These complications can add considerable cost. For example, to treat cardiovascular diseases, a monthly course of aspirin, a statin, a beta-blocker, and an ACE inhibitor can cost 18 days' worth of wages in Malawi. ${ }^{36}$ The cost of treatment for complications and comorbidities can outweigh that of primary and secondary prevention of diabetes. ${ }^{37}$ The total treatment costs for diabetes and its complications thus become a leading barrier for patients to receive proper, comprehensive diabetes care. ${ }^{38}$ As described above, the high out-of-pocket healthcare payments, loss of familyincome-associated disability, premature death, in addition to expenditure on daily medications and treatments of diabetic complications due to being uninsured are major sources of catastrophic expenditures imposed on diabetic patients without financial protection for themselves and their family members.

While some efforts have provided short-term support for the immediate needs of patients with diabetes, the long-term needs of patients with diabetes could be better managed through integration within the broader health system. The high cost of providing comprehensive care for diabetes requires risk mitigation which can be achieved through inclusion within broader population-level insurance programs which cover both sick and non-sick enrollees. As described earlier, the costs of diabetes care to the individual are untenable for many patients in need of care. However, through novel risk mitigation strategies, this cost could be spread across a much larger population of sick and non-sick populations through governmentally backed universal health coverage programs which aim to provide health coverage to all citizens. ${ }^{39}$ The ultimate aims of universal health coverage are to cover beneficiaries, maximize financial protection, and protect individuals from catastrophic health expenditures. ${ }^{40}$ Despite the growing popularity of universal health coverage in policy discussions, less than $10 \%$ of the population in SSA is covered under these schemes and there has been limited translation of policy into patient impact. ${ }^{39}$ Even though few examples exist within SSA with regard to successful financial protection schemes for patients living with diabetes, examples from a recent report demonstrate initial successes with innovative financial protection programs such as the health equity funds for the poor initiative in Cambodia or the universal health coverage scale-up initiative in Kenya, Turkey, Mexico, Thailand, and China. ${ }^{41}$
The economic burden of diabetes on individuals and society is substantial. Isolated, vertical funding for diabetes alone is not sustainable. One potential pathway for resolving these issues is to leverage the infrastructure and resources needed to address the multiple complications of diabetes to support an integrated chronic disease care system, which is responsive to many emerging healthcare needs in SSA. Other potential pathways include the creation of insurance plans that insure against long-term cost of diabetes, compulsory social health insurance programs, tax-based financing insurance programs, subsidies for healthy substitutes, or population-based targeted interventions (i.e. taxes on alcohol, tobacco, sweetened beverages). ${ }^{41}$ Through this diagonal approach, the costs and benefits of diabetes can also be shared across a much larger pool of patients. This approach could reduce the costs of care per patient by maximizing the economies of scale within the healthcare system.

\section{Health Workforce}

A severe shortage of trained healthcare providers is observed in many SSA countries, ${ }^{42,43}$ with an average of 15.5 physicians per 100,000 people in $\mathrm{SSA},{ }^{42}$ compared to 245 physicians per 100,000 people in the United States in $2011 .{ }^{44}$ In 2010, Tanzania has a physician density of 0.6 per 100,000 people, Liberia (1.2), Ethiopia (2.3), Ghana (8.0), Congo (9.2), and Nigeria (32.8). ${ }^{45}$ The Health, Nutrition, and Population Project in Malawi conducted between 1991 and 2000 concluded that imbalanced and understaffed facilities can lead to poor quality of healthcare. ${ }^{46}$ In addition, it has been documented that healthcare workers' capacity to manage diabetes is still suboptimal in various countries across SSA with regard to training, diagnosis capability, knowledge about treatment protocols and medication prescriptions, as well as management of complications and comorbidities of diabetes. ${ }^{47}$

One of the solutions to improve the health workforce shortage and quality of care is task shifting. Task shifting is defined as delegating tasks to workers with narrow, specific training for a particular task. ${ }^{48}$ Task shifting can increase productivity, reduce training time, increase patients' access to healthcare, and improve quality of care. ${ }^{48}$ Training other healthcare professionals for certain aspects of diabetes care can help achieve the aforementioned goals due to the cross-cutting nature of the disease. Through shifting the more time-intensive routine care activities to other members of the healthcare team, physicians can concentrate their efforts on patients with 
complications who need more in-depth review and treatment from providers with extensive clinical experience.

For example, to better manage diabetes-associated complications and comorbidities, peers or community health workers trained to monitor blood glucose levels could also be cross-trained to monitor blood pressure, conduct other point-of-care testing, or even prescribe or adjust medications. The efficacy of this approach has been consistently documented across SSA. ${ }^{49}$ The relationship established between patients and community health workers can further strengthen patient engagement in their health decision-making and connect the rural communities with health systems. ${ }^{50}$ Moreover, in rural South Africa, the Hlabisa project found that nurse-led care was associated with positive outcomes in glucose management given well-defined protocols. ${ }^{51}$ Nurse-led diabetes care successfully decreased A1C levels by 33\% from baseline in 18 months of time. ${ }^{52}$ The creation of a community peer leader program for diabetes care has also demonstrated improved levels of A1C and systolic blood pressure. ${ }^{53}$ Nutritionists and dietitians represent another vital component of the diabetes healthcare team that must be effectively incorporated to introduce contextualized culturally appropriate guidance to optimize the prevention and management of diabetes in SSA. ${ }^{54}$

Given above examples of several cadres of health workers working in isolation to improve the quality of diabetes care, it must be noted that real-world examples have shown that despite significant barriers such as hierarchal structure and time and financial resource constraints, creating interdisciplinary teams of health professionals (i.e. doctors, nurses, dieticians, nutritionists) and social scientists (i.e. anthropologists, psychologists, sociologists) is possible and can improve treatment outcomes for patients living with diabetes. ${ }^{55}$

In addition to task shifting, integrating diabetes care into the broader health system leverages the existing workforce to provide comprehensive healthcare. It is more cost-effective to train existing healthcare providers than to hire new ones. Home-based HIV counselors in Kenya have been trained to also screen for diabetes and hypertension in the community. ${ }^{56}$ As a result, due to the cross-cutting nature of disease, a healthcare workforce that is trained to manage diabetes and its complications could also manage a wide variety of other diseases frequently found throughout the population (Figure 1). The integration of diabetes care into the broader health system using a diagonal approach can promote universal patient access to a trained healthcare workforce and lead to improvement of quality of care across SSA.

\section{Health Information Systems}

High-quality treatment for diabetes and its associated complications and comorbidities requires sophisticated information management systems. However, in most SSA countries, there is limited access to electronic health information systems (EHIS). Several challenges and barriers have been identified, including high cost of set-up and maintenance, poor network infrastructure, and lack of comfort among the users. ${ }^{57}$ Consequently, many health systems in South Africa still use paper-based documentation systems, which can lead to poor patient care. ${ }^{58}$

To improve patient health outcomes, workflow efficiencies, and cost-effectiveness, the establishment of an EHIS is vital. ${ }^{59}$ Various technologies have been developed to advance EHIS, such as electronic medical records, telemedicine, e-Health, and computerized clinical decision-support systems. ${ }^{59}$ Telemedicine and electronic health record have been shown to reduce overall healthcare cost in South Africa and Kenya, respectively. ${ }^{60,61}$ More specifically, the implementation of EHIS for diabetes care can lead to improved diabetes quality metrics, including an increase in the percentage of patients receiving annual $\mathrm{A} 1 \mathrm{C}$, blood pressure, lipid, foot, urine, and eye examinations in LMICs. ${ }^{62}$ Additionally, the use of electronic records can reduce prescription errors, flag abnormal laboratory results, and allow access to patients records by multiple viewers. ${ }^{57}$ All the aforementioned technologies can provide timely and accurate information on individual patients, which is critical in organizing the provision of comprehensive care of diabetes. ${ }^{63}$ In addition to improving clinical services, EHIS can support data collection for monitoring, evaluation, quality improvement, and research purposes. EHIS are generally not disease-specific, but rather function to support the information needs of the entire health system. In Rwanda, an electronic medical record system was implemented to serve all patients with HIV/AIDS, tuberculosis, hypertension, diabetes, and other chronic conditions. ${ }^{64}$ And because of the cross-cutting nature of diabetes, the implementation of an EHIS will not only benefit care for diabetes, but also the quality of care for other related conditions such as cardiovascular diseases, renal diseases, and various types of infectious diseases. It is therefore essential to take a diagonal approach, integrating diabetes care into a broader health system strengthening effort, catalyzing the advancement of electronic health information infrastructure in SSA 
more generally. An integrated EHIS provides the seamless clinical and programmatic data required to effectively care for diabetes and other associated illnesses across the disease continuum and throughout the life course. Scaling up diabetes care via a diagonal, health systems approach helps promote the advancement of EHIS for the benefit of the health system as a whole, while simultaneously improving the quality of care for diabetes.

In addition to EHIS, SSA has been able to establish its own Africa Health Observatory as part of the WHO initiative - Global Health Observatory (GHO). ${ }^{65}$ With this rich data source, many countries in SSA participate to regularly share real-time data on global health indicators, including data, statistics, health situation analysis by country, and information about diseases and health indicators. Besides EHIS, investing in a transparent health information systems such as the Africa Health Observatory increases the accountability and quality of collected data, while also providing updated information on disease epidemiology, health indicators, and infrastructure indicators, EHIS and global health observatories present as an efficient allocation of financial resources to address diabetes in SSA.

\section{Supply Chains}

Access to essential medications and diagnostic tests is a vital element for the delivery of high quality of care for patients in SSA. To provide effective therapies for both communicable and NCDs, many countries have established the national Essential Medicines List (EML). ${ }^{66}$ Even with the list, the average drug availability in public sector facilities in SSA is merely $38.2 \% .{ }^{35}$ When medications are not available in the public sector, patients would have to either forgo the treatments or go to the private sectors for higher-priced drugs, where availability is still not guaranteed.

Essential treatment modalities of diabetes and its complications are composed of various classes of medications, including insulin and oral hypoglycemics, anti-hypertensives, statins, and aspirin. However, almost $20 \%$ of the anti-hypertensive medications found in Rwanda were substandard and $70 \%$ of them had poor stability. ${ }^{67}$ Some patients may need insulin as well, which presents life-threatening challenges to patients who depend on insulin to survive. ${ }^{68}$ The International Insulin Foundation has conducted studies in Zambia, Mali, and Mozambique and found the causes of barriers to accessing essential medicines can be linked not only to affordability and accessibility issues, but also to issues related to access to syringes, diagnostic tools, and medications for diabetes- associated comorbidities. ${ }^{69}$ In terms of diagnostic capacity, only $6 \%$ of health centers in Mozambique were qualified to test blood glucose. ${ }^{69}$ To effectively manage diabetes, diagnostics for other parameters such as blood pressure, lipid panels, and renal function tests are also required. The WHO accordingly suggested to combine management of diabetes, cardiovascular disease, and even HIV/AIDS and tuberculosis to yield superior health outcomes. ${ }^{7}$

All these impediments reinforce the importance of establishing a robust, consistent, and high-quality supply chain to deliver medications, supplies, and diagnostic tools for comprehensive diabetes care. Due to the complexity of diabetes, its supply chains should be integrated into the whole health system rather than for disease-specific entities. Building a supply chain solely for insulin or syringes is not sustainable and cost-effective. One innovative solution that can provide a back-up supply of medications when public-sector supply chains break down is the Revolving Drug Fund (RDF) model that has been implemented in multiple SSA countries. ${ }^{70}$ Within the Kenyan implementation, the RDF provides sustainable access to medications when government pharmacies are out of stock, and has been shown to increase medication availability by at least $50 \%{ }^{71}$ Comprehensive diabetes care requires multifactorial interventions including sustainable access to medications, medical supplies, and diagnostic tools for blood sugar, lipid, and renal function testing. With appropriate use of medications and medical supplies, the burden of diabetes can be significantly reduced. Consequently, it is imperative to integrate supply chains for diabetes medicines and supplies with those for other essential medicines in order to effectively ameliorate disparities in access to essential medicines for all chronic diseases.

\section{Service Delivery}

Strengthening health service delivery is critical in providing sustainable, comprehensive, and cost-effective diabetes care. In Cape Town, South Africa, the quality of care was poor for the delivery of diabetes care. ${ }^{72}$ Renal function tests were only performed in $39.5 \%$ of the cases and HbA1C was only tested for $37 \%$ of the patients. ${ }^{72}$ In Kenya, the quality of diabetes care was also poor at various levels of the healthcare system, and less than $20 \%$ of the patients achieved controlled A1C levels. ${ }^{73}$ The challenges of establishing efficient and effective service delivery mechanisms for diabetes care are the lack of an adequate health care workforce, evidence-based 
guidelines, medical supplies, diagnostic tools, and firstline medications. ${ }^{74}$ In Tanzania, only 13\% of the facilities have well-developed guidelines to assist less-specialized and educated clinicians to provide diabetes care. ${ }^{74}$

To improve the quality of care for diabetes, evidence suggests that integrating service delivery with screening, education, and care for other chronic illnesses can be the solutions. Recently, this has been attempted through various Universal Health Coverage initiatives through primary healthcare strengthening in SSA countries including Kenya, Rwanda, Zambia, Ghana, Ethiopia, and others. Even though essential care services have been expanded significantly, compared to other WHO regions, SSA still has the lowest performance on tracer indicators of coverage of essential services. ${ }^{39}$ However, progress continues to be made through screening programs for diabetes in Uganda, through which diabetes screening was integrated into existing communitywide HIV testing facilities, which promoted patient engagement in healthcare. ${ }^{75}$ Multi-disease testing in community settings offers advantages by providing patient access to comprehensive treatment options and screening in the rural areas, which further improves health outcomes. ${ }^{75,76}$ It additionally has been shown to reduce stigma experienced by patients with HIV/AIDS. ${ }^{75}$ Furthermore, in eight African countries including Tanzania, Cameroon, Mozambique, Kenya, Uganda, Senegal, Zimbabwe, and Zambia, the IDF

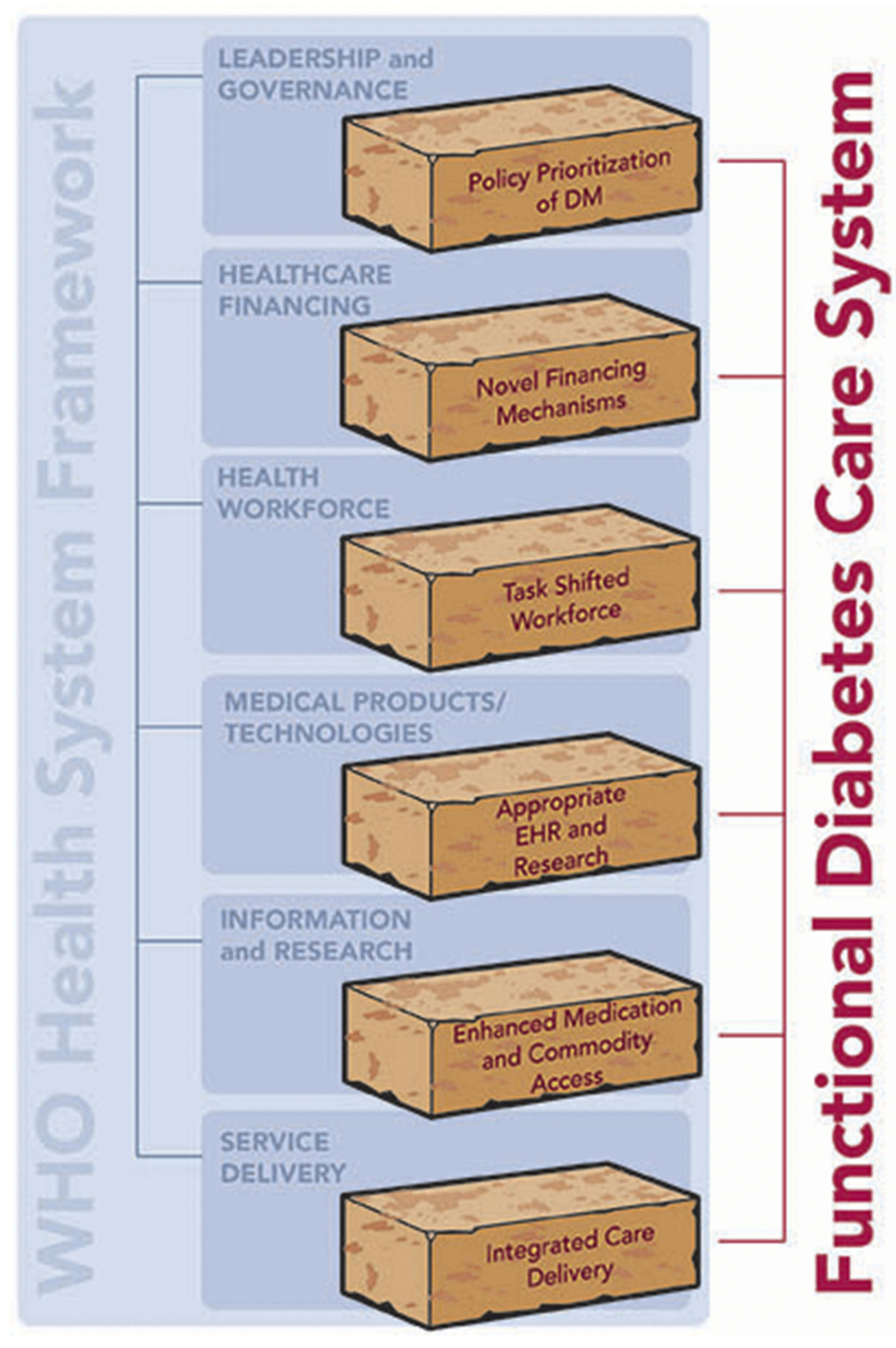

Figure 2 WHO health system building blocks as a framework for functional diabetes care system. 
established standardized education for diabetes awareness and patient self-management. ${ }^{77}$ Patients also tend to move between primary, secondary, and tertiary care facilities due to the complexity and severity of diabetes-associated complications or comorbidities. ${ }^{78}$ To improve service delivery for diabetes care, it is therefore essential to simultaneously address the intertwining challenges and concerns from all of the WHO building blocks as diabetes care requires crosscutting interventions and a well-functioning, comprehensive health system at multiple levels. Integrating diabetes care through a diagonal health systems strengthening approach is a promising solution to the inefficient and poor quality of service delivery that is the current reality in SSA.

\section{Potential Use Of The Diagonal Approach To Address Other NCD Care Programs}

As outlined in Figure 2, we utilize the six World Health Organization (WHO) health system building blocks - leadership and governance, financing, health workforce, health information systems, supply chains, and service delivery - as a framework for addressing the importance of implementing and scaling diabetes care within a diagonal approach focused on health system strengthening. We discuss the successes and challenges of this approach, outline opportunities for future care programming and research, and highlight how this approach may lead to the improvement in the quality of care for diabetes and other chronic diseases across SSA. These challenges and potential solutions are summarized in Table 1, which helps illustrate how an effective response to diabetes-related challenges could simultaneously help address the needs for other NCDs.

\section{Conclusions}

This paper illustrates the benefits, importance, and urgency of diagonally integrating diabetes care into the broader health system in order to improve the quality of care for diabetes and also other chronic illnesses. This diagonal approach has positive impacts on all six of the WHO health system building blocks, and simultaneously, addressing barriers and challenges in each of these critical health system functions is necessary to provide comprehensive,

Table I Shared Challenges Between Diabetes And Other NCDs In SSA, Potential Solutions Through The Use Of A Diagonal Approach And Feasibility

\begin{tabular}{|c|c|c|}
\hline $\begin{array}{l}\text { Shared Challenges Between Diabetes And } \\
\text { Other NCDs In SSA }\end{array}$ & Potential Solutions & Feasibility \\
\hline $\begin{array}{l}\text { Limited translation of policy declarations into } \\
\text { tangible improvements in patient outcomes }\end{array}$ & $\begin{array}{l}\text { Introduce policies which holistically address the drivers of } \\
\text { NCDs and link policy advocacy to appropriate resource } \\
\text { allocation }\end{array}$ & High (long-term impact) \\
\hline Increasing burden of disease & $\begin{array}{l}\text { Implementation of comprehensive prevention and awareness } \\
\text { programs }\end{array}$ & High (long-term impact) \\
\hline $\begin{array}{l}\text { Lack of efforts to introduce vertical programs to } \\
\text { address specific NCDs }\end{array}$ & $\begin{array}{l}\text { Utilize a diagonal approach that improves the responsiveness } \\
\text { of the health system to NCDS }\end{array}$ & High (long-term impact) \\
\hline $\begin{array}{l}\text { Complications of diseases impact multiple organ } \\
\text { systems }\end{array}$ & $\begin{array}{l}\text { NCD care benefits from enhancements in care designed to } \\
\text { address diabetes complications }\end{array}$ & High (long-term impact) \\
\hline $\begin{array}{l}\text { Limited funding from national governments to } \\
\text { specifically address NCDs }\end{array}$ & $\begin{array}{l}\text { Incorporation of NCDs within government-backed universal } \\
\text { health coverage programs which distribute costs across the } \\
\text { entire population }\end{array}$ & High (immediate impact) \\
\hline $\begin{array}{l}\text { Inefficient, ineffective supply chain systems with } \\
\text { limited access to vital commodities }\end{array}$ & $\begin{array}{l}\text { Introduction of novel supply chain systems which subsidize } \\
\text { costs and ensure uninterrupted availability }\end{array}$ & High (immediate impact) \\
\hline $\begin{array}{l}\text { Limited availability of a formally trained health } \\
\text { workforce capable of managing the growing } \\
\text { population with these diseases }\end{array}$ & $\begin{array}{l}\text { Scale-up of task-shifted models for chronic disease service } \\
\text { delivery which align the acuity of patient needs with the } \\
\text { appropriate level of provider }\end{array}$ & High (immediate impact) \\
\hline Poorly organized data for NCDs & $\begin{array}{l}\text { Introduction of electronic health information systems to } \\
\text { improve tracking, quality of care, and planning }\end{array}$ & High (immediate impact) \\
\hline
\end{tabular}


high-quality care for a cross-cutting, complex, lifelong disease such as diabetes. The incorporation of diabetes care can strengthen existing health systems in SSA through policy prioritization, innovative financing mechanisms, task-shifting of workforce, EHIS, seamless and secure access to essential medicines and diagnostic tools, and comprehensive service delivery. More importantly, this new model of care for diabetes attempts to integrate a social-medical-preventive approach to a historical bio-medical-curative approach, and has the promise to not only enhance the biological outcomes but also social outcomes for patients living with diabetes. The long-term goal of integrating sustainable care for diabetes and its associated complications into all the vital health system functions is to improve health outcomes for all patient populations in SSA.

\section{Acknowledgments}

There was no specific funder for this manuscript. TM, AG, JL, SP work with the Academic Model Providing Access to Healthcare (AMPATH), which is supported by the President's Emergency Plan for AIDS Relief (PEPFAR) through the United States Agency for International Development (USAID) under the terms of Cooperative Agreement No. AID-623-A-12-0001. The contents of this manuscript are the sole responsibility of the authors and do not necessarily reflect the views of USAID or the United States Government.

\section{Disclosure}

SP serves as a consultant for Abbott but this activity is unrelated to the work described in this paper. The authors report no other conflicts of interest in this work.

\section{References}

1. GBD 2017 Risk Factor Collaborators. Global, regional, and national comparative risk assessment of 84 behavioural, environmental and occupational, and metabolic risks or clusters of risks for 195 countries and territories, 1990-2017: a systematic analysis for the Global Burden of Disease Study 2017. Lancet Lond Engl. 2018;392(10159):19231994. doi:10.1016/S0140-6736(18)32225-6

2. International Diabetes Federation. Regional fact sheet: Africa | World Diabetes Foundation. Available from: https://www.worlddiabetesfoun dation.org/files/regional-fact-sheet-africa. 2017. Accessed February 26, 2019.

3. Assah F, Mbanya JC. Diabetes in sub-Saharan Africa. In: Dagogo-Jack $\mathrm{S}$, editor. Diabetes Mellitus in Developing Countries and Underserved Communities. Cham: Springer International Publishing; 2017:33-48. doi:10.1007/978-3-319-41559-8_3
4. Atun R, Davies JI, Gale EAM, et al. Diabetes in sub-Saharan Africa: from clinical care to health policy. Lancet Diabetes Endocrinol. 2017;5(8):622-667. doi:10.1016/S2213-8587(17)30181-X

5. de-Graft Aikins A, Unwin N, Agyemang C, Allotey P, Campbell C, Arhinful D. Tackling Africa's chronic disease burden: from the local to the global. Glob Health. 2010;6:5. doi:10.1186/1744-8603-6-5

6. International Diabetes Federation - Complications. Available from: https://www.idf.org/aboutdiabetes/complications.html. Accessed July 9, 2019.

7. World Health Organization. WHO Global Report on Diabetes. WHO. 2016. Available from: http://www.who.int/diabetes/global-report/en/. Accessed February 27, 2019.

8. Pastakia SD, Pekny CR, Manyara SM, Fischer L. Diabetes in subSaharan Africa - from policy to practice to progress: targeting the existing gaps for future care for diabetes. Diabetes Metab Syndr Obes Targets Ther. 2017;10:247-263. doi:10.2147/DMSO.S126314

9. World Health Organization, ed. Monitoring the Building Blocks of Health Systems: A Handbook of Indicators and Their Measurement Strategies. Geneva: World Health Organization; 2010.

10. Knaul FM, Bhadelia A, Atun R, Frenk J. Achieving effective universal health coverage and diagonal approaches to care for chronic illnesses. Health Aff Proj Hope. 2015;34(9):1514-1522. doi:10.1377/ hlthaff.2015.0514

11. Orenstein WA, Seib K. Beyond vertical and horizontal programs: a diagonal approach to building national immunization programs through measles elimination. Expert Rev Vaccines. 2016;15 (7):791-793. doi:10.1586/14760584.2016.1165614

12. World Health Organization. WHO | Vertical-Horizontal Synergy of the Health Workforce. WHO. 2005. Available from: https://www. who.int/bulletin/volumes/83/4/editorial10405/en/. Accessed February $28,2019$.

13. Frenk J. Bridging the divide: global lessons from evidence-based health policy in Mexico. Lancet Lond Engl. 2006;368(9539):954961. doi:10.1016/S0140-6736(06)69376-8

14. Sepúlveda J, Bustreo F, Tapia R, et al. Improvement of child survival in Mexico: the diagonal approach. Lancet Lond Engl. 2006;368(9551):2017-2027. doi:10.1016/S0140-6736(06)69569-X

15. Uplekar M, Raviglione MC. The "vertical-horizontal" debates: time for the pendulum to rest (in peace)? Bull World Health Organ. 2007;85(5):413-414. doi:10.2471/blt.07.041756

16. Frenk J. Bridging the divide: comprehensive reform to improve health in Mexico. Lect WHO Comm Soc Determinants Health Nairobi. 2006;17.

17. Ooms G, Van Damme W, Baker BK, Zeitz P, Schrecker T. The "diagonal" approach to global fund financing: a cure for the broader malaise of health systems? Glob Health. 2008;4:6. doi:10.1186/17448603-4-6

18. Gounder CR, Chaisson RE. A diagonal approach to building primary healthcare systems in resource-limited settings: womencentred integration of HIV/AIDS, tuberculosis, malaria, $\mathrm{MCH}$ and NCD initiatives. Trop Med Int Health TM IH. 2012;17(12):14261431. doi:10.1111/j.1365-3156.2012.03100.x

19. Hagan JE, Greiner A, Luvsansharav U-O, et al. Use of a diagonal approach to health system strengthening and measles elimination after a large nationwide outbreak in Mongolia. Emerg Infect Dis. 2017;23:13. doi:10.3201/eid2313.170594

20. Kirigia JM, Kirigia DG. The essence of governance in health development. Int Arch Med. 2011;4:11. doi:10.1186/1755-7682-4-11

21. Beran D, Yudkin JS. Diabetes care in sub-Saharan Africa. Lancet Lond Engl. 2006;368(9548):1689-1695. doi:10.1016/S0140-6736 (06)69704-3

22. Poore S, Foster A, Zondervan M, Blanchet K. Planning and developing services for diabetic retinopathy in Sub-Saharan Africa. Int $J$ Health Policy Manag. 2015;4(1):19-28. doi:10.15171/ijhpm.2015.04 
23. WHO | Tool for assessment of diabetes and diabetic retinopathy WHO. Available from: http://www.who.int/blindness/publications/ tadds/en/. Accessed July 9, 2019.

24. Cooke JG. Public health in Africa - a report of the CSIS global health policy center. J Public Health Afr. 2010;1:1. doi:10.4081/jphia.2010.e8

25. Labadarios D, Steyn NP, Mgijima C, Daldla N. Review of the South African nutrition policy 1994-2002 and targets for 2007: achievements and challenges. Nutr Burbank Los Angel Cty Calif. 2005;21 (1):100-108. doi:10.1016/j.nut.2004.09.014

26. Naik R, Kaneda T. Noncommunicable Diseases in Africa: Youth are Key to Curbing the Epidemic and Achieving Sustainable Development. Population Reference Bureau; 2015:12. Available from: www.prb.org.

27. WHO | About Social Determinants of Health. WHO; 2019. Available from: http://www.who.int/social_determinants/sdh_defini tion/en/. Accessed July 9, 2019.

28. Hill J, Nielsen M, Fox MH. Understanding the social factors that contribute to diabetes: a means to informing health care and social policies for the chronically ill. Perm J. 2013;17(2):67-72. doi:10. 7812/TPP/12-099

29. Engelgau MM, Rosenthal JP, Newsome BJ, Price L, Belis D, Mensah GA. Noncommunicable diseases in low- and middle-income countries. Glob Heart. 2018;13(2):131-137. doi:10.1016/j.gheart.2018.05. 001

30. Kirigia JM, Sambo HB, Sambo LG, Barry SP. Economic burden of diabetes mellitus in the WHO African region. BMC Int Health Hum Rights. 2009;9:6. doi:10.1186/1472-698X-9-6

31. Beran D, Ewen M, Laing R. Constraints and challenges in access to insulin: a global perspective. Lancet Diabetes Endocrinol. 2016;4 (3):275-285. doi:10.1016/S2213-8587(15)00521-5

32. Beran D, McCabe A, Yudkin JS. Access to medicines versus access to treatment: the case of type 1 diabetes. Bull World Health Organ. 2008;86(8):648-649. doi:10.2471/blt.07.048710

33. Onyiriuka N, Ezomo O, Onyiriuka R. Cost of treating Insulin-requiring diabetes in children and adolescents. Journal of Institute of Medicine. 2013;34(1):2-8. doi:10.3126/jiom.v34i1.9115

34. Okoronkwo IL, Ekpemiro JN, Okwor EU, Okpala PU, Adeyemo FO. Economic burden and catastrophic cost among people living with type2 diabetes mellitus attending a tertiary health institution in south-east zone, Nigeria. BMC Res Notes. 2015;8:527. doi:10.1186/s13104-015-1489-x

35. Health Action International and World Health Organization. Medicine Prices, Availability, Affordability \& Price Components. Available from: http://www.haiweb.org/medicineprices/2017Medicine Prices, Availability, Affordability \& Price Components Available from: http://www.haiweb.org/medicineprices/Accessed February 28, 2019.

36. Mendis S, Fukino K, Cameron A, et al. The availability and affordability of selected essential medicines for chronic diseases in six lowand middle-income countries. Bull World Health Organ. 2007;85 (4):279-288. doi:10.2471/BLT.06.033647

37. Hall V, Thomsen RW, Henriksen O, Lohse N. Diabetes in Sub Saharan Africa 1999-2011: epidemiology and public health implications. A systematic review. BMC Public Health. 2011;11:564. doi:10.1186/1471-2458-11-564

38. Alouki K, Delisle H, Besançon S, et al. Simple calculator to estimate the medical cost of diabetes in sub-Saharan Africa. World J Diabetes. 2015;6(16):1312-1322. doi:10.4239/wjd.v6.i16.1312

39. The World Bank. Tracking Universal Health Coverage: 2017 Global Monitoring Report. The World Bank; 2017:1-88. Available from: http://documents.worldbank.org/curated/en/640121513095868125/ Tracking-universal-health-coverage-2017-global-monitoring-report. Accessed February 28, 2019.

40. World Health Organization. WHO $\mid$ Health Systems Financing: The Path to Universal Coverage. WHO; 2010. Available from: /entity/ whr/2010/en/index.html.

41. Jan S, Laba T-L, Essue BM, et al. Action to address the household economic burden of non-communicable diseases. Lancet Lond Engl. 2018;391(10134):2047-2058. doi:10.1016/S0140-6736(18)30323-4
42. Liese BH, Dussault G. The State of the Health Workforce in SubSaharan Africa. Evidence of Crisis and Analysis of Contributing Factors. 2004. Available from: http://documents.worldbank.org/ curated/en/412051468002680722/The-State-of-the-health-workforcein-Sub-Saharan-Africa-evidence-of-crisis-and-analysis-of-contribut ing-factors

43. Global Health Workforce Alliance and World Health Organization. $A$ Universal Truth: No Health Without a Workforce. Third Global Forum on Human Resources for Health Report. 2013:104. Available from: https://www.who.int/workforcealliance/knowledge/resources/hrhre port2013/en/. Accessed February 28, 2019.

44. Central Intelligence Agency. Field Listing: physicians density - the world factbook. Available from: https://www.cia.gov/library/publica tions/resources/the-world-factbook/fields/359.html. Accessed February $28,2019$.

45. Tankwanchi ABS, Ozden C, Vermund SH. Physician emigration from sub-Saharan Africa to the United States: analysis of the 2011 AMA physician masterfile. PLoS Med. 2013;10(9):e1001513. doi:10.1371/ journal.pmed.1001513

46. The World Bank. Malawi - Population, Health and Nutrition Project. The World Bank; 2001. 63. Available from: http://documents.world bank.org/curated/en/278651468300680324/Malawi-PopulationHealth-and-Nutrition-Project. Accessed February 28, $2019 .$.

47. Nuche-Berenguer B, Kupfer LE. Readiness of sub-Saharan Africa healthcare systems for the new pandemic, diabetes: a systematic review. J Diabetes Res. 2018;2018:9262395. doi:10.1155/2018/9262395

48. Fulton BD, Scheffler RM, Sparkes SP, Auh EY, Vujicic M, Soucat A. Health workforce skill mix and task shifting in low income countries: a review of recent evidence. Hum Resour Health. 2011;9:1. doi:10. 1186/1478-4491-9-1

49. Webel AR, Okonsky J, Trompeta J, Holzemer WL. A systematic review of the effectiveness of peer-based interventions on healthrelated behaviors in adults. Am J Public Health. 2010;100(2):247253. doi:10.2105/AJPH.2008.149419

50. Smith DL, Bryant JH. Building the infrastructure for primary health care: an overview of vertical and integrated approaches. Soc Sci Med 1982. 1988;26(9):909-917.

51. Gill GV, Price C, Shandu D, Dedicoat M, Wilkinson D. An effective system of nurse-led diabetes care in rural Africa. Diabet Med $\mathrm{J} \mathrm{Br}$ Diabet Assoc. 2008;25(5):606-611. doi:10.1111/j.1464-5491.2008.02 421.x

52. Lekoubou A, Awah P, Fezeu L, Sobngwi E, Kengne AP. Hypertension, diabetes mellitus and task shifting in their management in sub-Saharan Africa. Int $J$ Environ Res Public Health. 2010;7(2):353-363. doi:10.3390/ijerph7020353

53. Park PH, Wambui $\mathrm{CK}$, Atieno $\mathrm{S}$, et al. Improving diabetes management and cardiovascular risk factors through peer-led self-management support groups in Western Kenya. Diabetes Care. 2015;38(8): e110-e111. doi:10.2337/dc15-0353

54. Lupafya PC, Mwagomba BLM, Hosig K, Maseko LM, Chimbali H. Implementation of policies and strategies for control of noncommunicable diseases in Malawi: challenges and opportunities. Health Educ Behav Off Publ Soc Public Health Educ. 2016;43(1Suppl):64S-9S. doi:10.1177/1090198115614313

55. McGill M, Blonde L, Chan JCN, et al. The interdisciplinary team in type 2 diabetes management: challenges and best practice solutions from real-world scenarios. J Clin Transl Endocrinol. 2017;7:21-27. doi:10.1016/j.jcte.2016.12.001

56. Pastakia SD, Ali SM, Kamano JH, et al. Screening for diabetes and hypertension in a rural low income setting in western Kenya utilizing home-based and community-based strategies. Glob Health. 2013;9:21. doi:10.1186/1744-8603-9-21

57. Akanbi MO, Ocheke AN, Agaba PA, et al. Use of electronic health records in sub-Saharan Africa: progress and challenges. $J$ Med Trop. 2012;14(1):1-6. 
58. Cline GB, Luiz JM. Information technology systems in public sector health facilities in developing countries: the case of South Africa. BMC Med Inform Decis Mak. 2013;13:13. doi:10.1186/1472-694713-13

59. Chaudhry B, Wang J, Wu S, et al. Systematic review: impact of health information technology on quality, efficiency, and costs of medical care. Ann Intern Med. 2006;144(10):742-752. doi:10.7326/ 0003-4819-144-10-200605160-00125

60. Braitstein P, Einterz RM, Sidle JE, Kimaiyo S, Tierney W. "Talkin' about a revolution": how electronic health records can facilitate the scale-up of HIV care and treatment and catalyze primary care in resource-constrained settings. J WHOAcquir Immune Defic Syndr 1999. 2009;52 (Suppl 1):S54-S57. doi:10.1097/QAI.0b013e3181bbcb67

61. Keeton C. Measuring the impact of e-health. Bull World Health Organ. 2012;90(5):326-327. doi:10.2471/BLT.12.020512

62. Ali MK, Shah S, Tandon N. Review of electronic decision-support tools for diabetes care: a viable option for low- and middle-income countries? J Diabetes Sci Technol. 2011;5(3):553-570. doi:10.1177/ 193229681100500310

63. Glasgow RE, Orleans CT, Wagner EH. Does the chronic care model serve also as a template for improving prevention? Milbank $Q$. 2001;79(4):579-612, iv-v.

64. Mutale W, Chintu N, Amoroso C, et al. Improving health information systems for decision making across five sub-Saharan African countries: implementation strategies from the African Health Initiative. BMC Health Serv Res. 2013;13(Suppl 2):S9. doi:10.1186/1472-696313-S2-S9

65. African Health Observatory. African Health Observatory. Available from: http://www.aho.afro.who.int/en. Accessed July 9, 2019.

66. World Health Organization. WHO | The Selection and Use of Essential Medicines. WHO; 2017. Available from: http://www.who. int/medicines/publications/essentialmedicines/trs-1006-2017/en/. Accessed February 28, 2019.

67. Twagirumukiza M, Cosijns A, Pringels E, Remon JP, Vervaet C, Van Bortel L. Influence of tropical climate conditions on the quality of antihypertensive drugs from Rwandan pharmacies. Am J Trop Med Hyg. 2009;81(5):776-781. doi:10.4269/ajtmh.2009.09-0109

68. Beran D, Yudkin JS. Looking beyond the issue of access to insulin: what is needed for proper diabetes care in resource poor settings. Diabetes Res Clin Pract. 2010;88(3):217-221. doi:10.1016/j. diabres.2010.03.029
69. Beran D, Yudkin JS, de Courten M. Access to care for patients with insulin-requiring diabetes in developing countries: case studies of Mozambique and Zambia. Diabetes Care. 2005;28(9):2136-2140. doi:10.2337/diacare.28.9.2136

70. Garner P. The Bamako Initiative. 1989;299. doi:10.1136/bmj.299.6 694.277

71. Manji I, Manyara SM, Jakait B, et al. The revolving fund pharmacy model: backing up the ministry of health supply chain in western Kenya. Int J Pharm Pract. 2016;24(5):358-366. doi:10.1111/ijpp.12 254

72. Isaacs A, Manga N, Grange CL, Hellenberg DA, Titus V, Sayed R. Quality of care and cost of prescriptions for diabetes and hypertension at primary healthcare facilities in the Cape Town Metropole. South Afr Fam Pract. 2015;57(3):187-193. doi:10.1080/20786190. 2014.976988

73. Mwavua SM, Ndungu EK, Mutai KK, Joshi MD. A comparative study of the quality of care and glycemic control among ambulatory type 2 diabetes mellitus clients, at a tertiary referral hospital and a regional hospital in central Kenya. BMC Res Notes. 2016;9:12. doi:10.1186/s13104-015-1826-0

74. Peck R, Mghamba J, Vanobberghen F, et al. Preparedness of Tanzanian health facilities for outpatient primary care of hypertension and diabetes: a cross-sectional survey. Lancet Glob Health. 2014;2 (5):e285-e292. doi:10.1016/S2214-109X(14)70033-6

75. Chamie G, Kwarisiima D, Clark TD, et al. Leveraging rapid community-based HIV testing campaigns for non-communicable diseases in rural Uganda. PLoS One. 2012;7(8):e43400. doi:10.1371/journal. pone. 0043400

76. Janssens B, Van Damme W, Raleigh B, et al. Offering integrated care for HIV/AIDS, diabetes and hypertension within chronic disease clinics in Cambodia. Bull World Health Organ. 2007;85(11):880885. doi: $10.2471 /$ blt.06.036574

77. Azevedo M, Alla S. Diabetes in sub-saharan Africa: Kenya, Mali, Mozambique, Nigeria, South Africa and Zambia. Int J Diabetes Dev Ctries. 2008;28(4):101-108. doi:10.4103/0973-3930.45268

78. Kane J, Landes M, Carroll C, Nolen A, Sodhi S. A systematic review of primary care models for non-communicable disease interventions in sub-Saharan Africa. BMC Fam Pract. 2017;18(1):46. doi:10.1186/ s12875-017-0613-5

\section{Publish your work in this journal}

Diabetes, Metabolic Syndrome and Obesity: Targets and Therapy is an international, peer-reviewed open-access journal committed to the rapid publication of the latest laboratory and clinical findings in the fields of diabetes, metabolic syndrome and obesity research. Original research, review, case reports, hypothesis formation, expert opinion and commentaries are all considered for publication. The manuscript management system is completely online and includes a very quick and fair peer-review system, which is all easy to use. Visit http://www.dovepress.com/testimonials.php to read real quotes from published authors.

Submit your manuscript here: https://www.dovepress.com/diabetes-metabolic-syndrome-and-obesity-targets-and-therapy-journal 